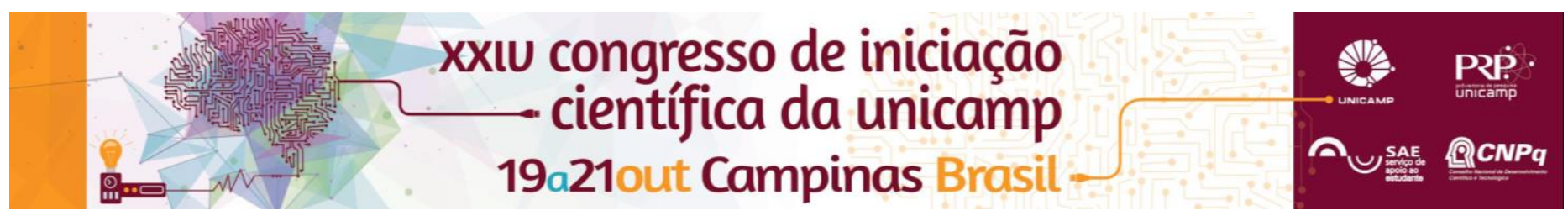

\title{
Características sóciodemográficas de Idosas Frágeis e Robustas Fisicamente.
}

\author{
Vivian C. de Lima, Ricardo A. C. Sampaio, Marco C. Uchida, Priscila Y. Sewo Sampaio.
}

\section{Resumo}

O envelhecimento é um conjunto de processos que determinam a perda da capacidade de adaptação ao meio ambiente. Nesse contexto, a fragilidade física pode aumentar a vulnerabilidade e a dependência dos idosos. O objetivo do estudo é comparar características sóciodemográficas de idosas de acordo com a fragilidade física (frágeis e robustas). Participaram do estudo 132 idosas da comunidade. Constatamos que idosas frágeis viviam mais sozinhas, saiam menos de cada durante a semana e relataram um histótico maior de quedas em comparação às robustas. O fato do idoso sair menos de casa e viverem sozinhos, pode resultar no aumento de problemas emocionais, ocasionando depressão, e, por vezes, aumentar o risco de quedas. Características encontradas nas idosas frágeis deste estudo, reforça a ideia multidimensional da síndrome da fragilidade e do processo de envelhecimento.

Palavras-chave: Envelhecimento, Idoso, Fragilidade Física.

\section{Introdução}

O envelhecimento é um conjunto de processos que determinam a perda da capacidade de adaptação ao meio ambiente. ${ }^{1}$ Nesse contexto se encontra a síndrome da fragilidade que pode comprometer ainda mais a manutenção da homeostase. Assim a fragilidade física $n$ envelhecimento pode aumentar a vulnerabilidade e dependência dos idosos. ${ }^{2}$ Isto posto, o objetivo do estud é comparar características sóciodemográficas de acord com a fragilidade física (frágeis e robustas), determinad pelo domínio físico do índice de fragilidade Kiho Checklist.

\section{Resultados e Discussão}

Um total de 132 idosas (idade média 68,48 \pm 6,14 anos recrutadas nos centros comunitários públicos concluíram estudo. O grupo Frágil Fisicamente foi composto por 2 participantes $(20,5 \%)$ sendo mais idosas do que as 10 voluntárias $(79,5 \%)$ do grupo Robusto Fisicament $(P<0,022)$. Confirmando estudos realizados no Brasi idosos frágeis costumam ter mais idade.2,3 Nossos resultados mostraram que a maioria das idosas robustas viviam com seus parceiros e/ou filhos, já as idosas frágeis em sua maioria viviam sozinhas (frágil 40,7\%, robusta $18,1 \%)$; condição que pode favorecer problemas emocionais e estresses psicológicos, resultando em depressão na maioria dos casos. ${ }^{4}$ Ao passo que $14,8 \%$ das frágeis saiam de casa menos de uma vez por semana, somente $2,9 \%$ das robustas relataram o mesmo. $O$ fato de o idoso sair menos de casa, pode ser a causa de falta de motivação. ${ }^{5,6}$ No número de quedas (no último ano) teve diferença significativa entre as idosas $(P<0,004)$, enquanto $23,9 \%$ das robustas relataram ter caído mais de uma vez, esse número atingiu $44,4 \%$ das frágeis. Segundo Yokoya et $\mathrm{al}^{7}$, o risco de quedas diminui a frequência do idoso em sair de casa. Variáveis como índice de massa corporal; escolaridade; estatus laboral; satisfação financeira; prática e frequência de atividade física não diferiram estatisticamente entre os grupos.

\section{Conclusões}

A fragilidade física é uma característica recorrente em idosos. No presente estudo constatamos que idosas frágeis saem menos de casa, vivem mais sozinhas e relatam mais quedas; reforçando, assim, a natureza multidimensional da síndrome da fragilidade. Na prática, profissionais da educação física devem planejar estratégias para enfrentar a fragilidade física em idosos como a oferta de atividades físicas que previnam a queda e atividades que promovam a sociabilização

Tabela 1. Características das Idosas Robustas e Frágeis Fisicamente $(n=132)$.

\begin{tabular}{cccc} 
Variáveis & $\begin{array}{c}\text { Frágil }(\mathbf{n}=27) \\
\% \text { Válida }(\mathbf{n})\end{array}$ & $\begin{array}{c}\text { Robusto }(\mathbf{n}=105) \\
\% \text { Válida }(\mathbf{n})\end{array}$ & P Valor \\
\hline Idade & $70.89 \pm 6.66$ & $67.87 \pm 5.87$ & 0.022 \\
Estrutura Familiar & & & 0.011 \\
Sozinho & $40.7(11)$ & $18.1(19)$ & \\
Parceiro & $11.1(3)$ & $25.7(27)$ & \\
Filho (s) & $18.5(5)$ & $25.7(27)$ & \\
Parceiro e Filho (s) & $18.5(5)$ & $22.9(24)$ & \\
Outros & $11.1(3)$ & $7.7(8)$ & \\
Sair de casa & &
\end{tabular}

Sair de casa

Menos de 1 vez

$14.8(4)$

$37(10)$

1 - 2 vezes

$14.8(4)$

3 - 4 vezes

$33.3(9)$

5 vezes ou mais

Quedas 0

1 vez

$3.7(1)$

2 vezes

$51.9(14)$

$22.2(6)$

$14.8(4)$

3 vezes

$7.4(2)$

$24.8(26)$

$27.6(29)$

$44.8(47)$

0.004

$76.2(80)$

$20(21)$

$2.9(3)$

4 vezes

\section{Agradecimentos}

$1(1)$

Estudo financiado pela CAPES, Programa Atração de Jovens Talentos, Ciência Sem Fronteiras, Protocolo 88887.065519/2014-00.

1 Spirduso, W. W. Dimensões Físicas do Envelhecimento. Barueri, SP: Manole, 2005. P.3-36

2 Fried, L.P.; Tangen, A. M.; Walston, J. et al. Frailty in older adults: evidence for a phenotype. J. Gerontol. 2001; 56A: M146-M157.

3 Sousa, A. C. P. A.; Dias, R. C.; Maciel, A. C. C.; Guerra, R. O. Frailty syndrome and associated factors in community-dwelling elderly in Northeast Brazil. A. Gerontol. Geriatr. 2012; 54: 95-101.

4 Bilotta, C.; Bowling, A.; Nicolini,P.; Casè, A.; Vergani, C. Quality of life in older outpatients living alone in the community in Italy. Health Social C. Community. 2012; 20: 32-41.

5 Sewo Sampaio, P. Y.; Sampaio, R. A. C. et al. Differences in lifestyle, physical performance and quality of life between frail and robust Brazilian communitydwelling elderly women. Geriatr Gerontol Int. 2015; 16: 829-835.

6 Spencer A. Ageing through occupation. Asian J Occupa Ther. 2001; 1: 15-21.

7 Yokoya T, Demura S, Sato S. Relationships between physical activity, ADL capability and fall risk in community-dwelling Japanese elderly population Environ Health Prev. Med 2007; 12: 25-32. 